\title{
Attitude toward Mental Illness and Psychiatry among the Medical Students and Interns in a Medical College
}

\author{
Ajay Risal, ${ }^{1}$ Pushpa Prasad Sharma, ${ }^{1}$ Seshananda Sanjel ${ }^{2}$ \\ 'Department of Psychiatry, ${ }^{2}$ Department of Community Medicine, Kathmandu University School of Medical Sciences (KUSMS), \\ Dhulikhel, Kavre, Nepal.
}

ABSTRACT

Introduction: Medical students tend to have a neutral or negative attitude to Psychiatry as a discipline. This study was initiated to explore the attitude towards mental illness and Psychiatry among the medical students and interns in Kathmandu University School of Medical Sciences.

Methods: A cross-sectional questionnaire based study was conducted among the medical students and interns at Dhulikhel Hospital.Two self-rating scales; Attitudes towards Psychiatry-30 and Attitudes to Mental Illnesswere used to assess attitudes towards mental illness and Psychiatryamong the total 159 subjects. Descriptive statistics and independent sample t-test were applied using SPSS16 for analysis.

Results: Among the total 159 subjects, 44 (27.7\%) were interns. Comparison of means of each item in Attitudes towards Psychiatry-30 and Attitudes to Mental Illnesswas done between males and females, medical students and interns, first semester and ninth semester students. Most of the subjects showed neutral attitude towards all the scoring items; though there were a few significant differences in mean scores of some items in group wise comparison.

Conclusions: Overall attitudes towards mental illness and psychiatry among the medical students and interns in our medical school were positive or neutral. A further study with medical students from differentinstitutionsis needed to get a detail nationwide picture.

Keywords: attitude; interns; medical students; mental illness; psychiatry.

\section{INTRODUCTION}

Mental health is an ignored subject in the field of medicine and public health all over the world. ${ }^{1-3}$ Medical students have neutral or negative attitude towards Psychiatry as a discipline and career choice. ${ }^{4-7}$ Possible factors may be demographic or socio-cultural; influencing students before their entrance into medical school or during their medical school years. ${ }^{8-11}$ Undergraduate educational programs are found unresponsive for psychiatric teaching in most institutions. ${ }^{12,13}$
Increasing manpower demand in Psychiatry is however not keeping pace with supply. 1,5,14-17 There are several studies showing significant positive changes in students' attitude after their psychiatric training, ${ }^{18-31}$ making doctors more responsive to the psychological dimension of physical illness. ${ }^{25,32-36}$

Keeping these paradoxical issues in mind, we intended to conduct a study aiming to assess and compare the

Correspondence: Dr. Ajay Risal, Kathmandu University Hospital Kathmandu University School of Medical Sciences, Dhulikhel, Kavre, Nepal. Email: drajayrisal@gmail.com, Phone: 9849550155. 
differences in attitude towards mental illnesses and Psychiatry among the medical students in different semesters and the interns undergoing compulsory rotatory internship.

\section{METHODS}

This descriptive cross-sectional questionnaire based study was conducted at Kathmandu University School of Medical Sciences (KUSMS) after getting approval from its Institutional Review Committee (IRC) in April 2011.

Study population included the medical students studying in KUSMS and the interns undergoing compulsory rotatory internship at Dhulikhel Hospital, Kathmandu University Hospital. The medical students were taken from three semesters; First semester (those entering the medical school), Sixth semester (those who completed their pre-clinical and just entering clinics) and Ninth semester (those who completed their Psychiatry course and appearing for Final University Exams), forming the three comparison groups. Interns were those who had cleared final MBBS and working in the different departments of the hospital.

Subjects were explained about the aims and objectives of the study being conducted in detail. Informed consent was taken after ensuring confidentiality of the information gathered in the questionnaires being used and clarifying that it would only be used for the purpose of the research intended.

Two self-rating scales were used in the study; Attitudes towards Psychiatry (ATP-30) ${ }^{37}$ and Attitudes to Mental Illness (AMI). ${ }^{23}$

ATP-30 is a 30-item, Likerttype scale looking at attitudes related to Psychiatry. Respondents express their agreement or disagreement to 30 items in terms of a five point scale: Strongly agree,Agree, Neutral, Disagree, and Strongly disagree. Response for 15 items meant to measure negative attitudes are scored as 1 to 5 , whereas, items measuring positive attitudes are scored from 5 to 1 respectively. Total score on the scale indicates positive or negative attitude, with high total score indicating positive and a low score indicating negative attitudes towards different aspects of Psychiatry.

Similarly, AMI is a 20-item questionnaire which focuses on attitudes towards the causes, treatment and consequences of mental illness and its impact on individuals and society. It also has the items constructed on a five-point Likert scale with a higher score suggesting a more favorable attitude. The scoring on some of the items is reversed to avoid response bias.

SPSS Version 16 was used for data entry and statistical analysis. Descriptive statistics was used to analyze socio-demographic factors while independent sample t-test was applied for comparison of mean scores obtained by the subject group on each item, and to know the statistical significance of the differences.

\section{RESULTS}

The sample consisted of 159 subjects of which 90 $(56.6 \%)$ were males and $69(43.4 \%)$ were females showing male dominance. Group-wise distribution showed $43(27 \%)$ of the respondents in First semester, $28(17.6 \%)$ in Sixth semester, $44(27.7 \%)$ in Final semester and $44(27.7 \%)$ interns. We also tried to document the presence of family history of mental illnesses in the subjects but 41 (almost 26\%) of the respondents did not enter it while 100 (around 68\%) reported absence of such family history. Hence we did not analyze the significance of this finding (Table 1).

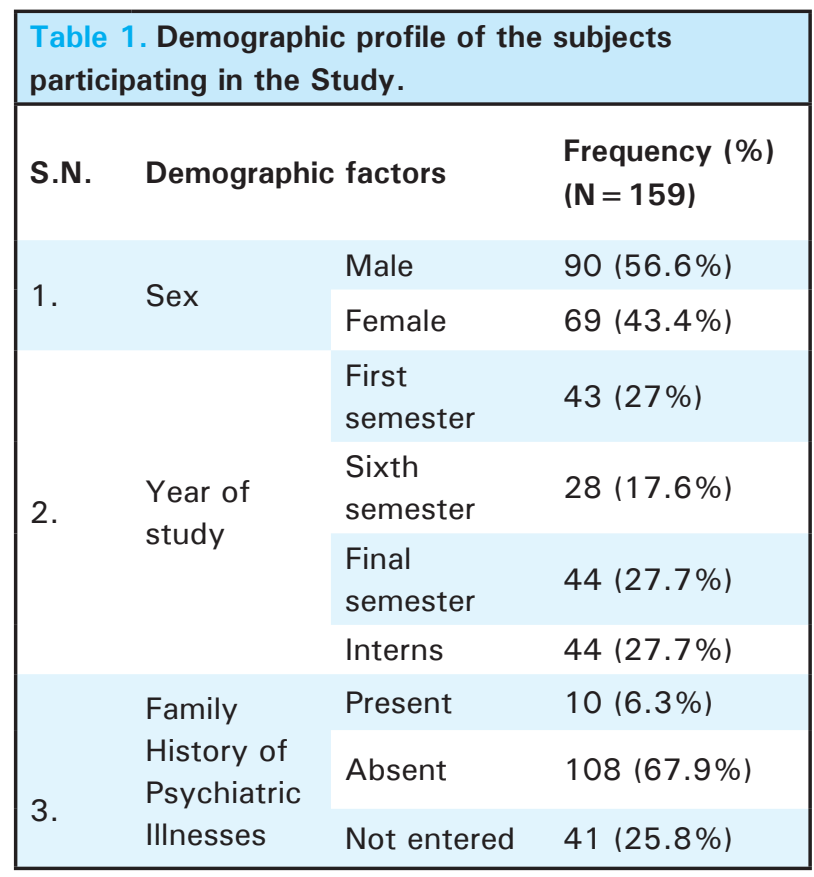

All of the subjects $(N=159)$ completed the ATP-30 questionnaire while $34 \mathrm{AMI}$ questionnaires were either incomplete or totally blank. Hence, only 125 AMI questionnaires were considered for analysis.

Group-wise comparison of the mean scores of each item in AMI questionnaire was done; comparison was made between males and females, medical students (as a whole group) and interns, as well as that between 
first semester and ninth semester medical students (Table 2). Similar comparison was doneamong the mean scores of each item in ATP-30 questionnaire (Table 3).

Most of the responses in AMI and ATP-30 were either positive or neutral among both the male and female groups. Some of the responses were significantly more positively stated by the males in comparison to the females $(P<0.05)$; most of the males strongly disagreed the opinion of banning ECT, and the statements "Psychiatric patients generally speaking are difficult to like" and "Alcohol abusers have no self-control" (Table 2). Significantly $(P<0.05)$, most females accepted the opinion that psychiatric treatment has become quite effective in recent years (Table 3 ).

Similarly, comparing the means of the responses in each AMI and ATP-30 items among medical students and interns also showed that the responses to almost all the items were either positive or neutral among both the groups. Significantly $(P<0.05)$, most of the interns denied the statement that mental illness was the result of adverse social circumstances, while medical students disagreed that care in the community for the mentally ill would put society at risk (Table 2). Significantly, more medical students considered Psychiatry to be an appealing field $(P<0.001)$; they agreed to the statement that psychiatric patients were more interesting to work with and to discover the cause of their illnesses $(P<0.05)$. Most of the medical students wanted to be a psychiatrist and disagreed the statement that psychiatric treatment would cause patients to worry too much about their symptoms $(\mathrm{P}<0.05)$ (Table 3$)$.

Comparison among the groups of first semester and ninth semester students revealed that most of the AMI and ATP-30 items were given a positive response. Significantly, the first semester students denied the opinion that mentally ill should not be given any responsible jobs and should be left independently $(P<0.05)$; and mental illnesses were genetic in origin $(P<0.001)$ (Table 2). Significantly $(P<0.01)$, most of the ninth semester students disagreed the statements that psychiatric hospitals were like prisons and psychiatrists were not equal to the doctors (Table 3 ).

\section{DISCUSSION}

Attitude is a hypothetical construct that represents an individual's like or dislike for an item; which may be positive, negative or neutral. It originates from judgments and has affective, behavioral and cognitive components. ${ }^{37}$ It also determines orientation towards a particular environment. ${ }^{5}$ So, orientation of the medical students towards management of psychological problem in physically ill patients during medical training shapes their attitude towards mental illnesses as a disease and Psychiatry as a medical subspecialty and determines the trend to choose Psychiatry as a career by future doctors. ${ }^{23,26,30,34}$

Lots of studies have been conducted to assess the attitude of medical students towards mental illness and Psychiatry using different scales. Some studies devised their own questionnaires, like those conducted in Spain, India, Iran, Canada and Pakistan. ${ }^{26,28,29,34,37,38}$ One study conducted in a Medical college at Eastern part of Nepal also developed a 20-item semi-structured questionnaire to assess the impact of a two-week training program on the awareness of medical students about Psychiatry. ${ }^{36}$ In a Greek Study, The Libertarian Mental Health Ideology Scale (LMHIS) was used to assess attitudes which measured the aspects of two competing conceptual frameworks in Psychiatry, the medical model and the radical psychosocial or "Szaszian-libertarian" position. ${ }^{8,39}$

ATP-30 was used in studies done at Pakistan and United Kingdom. 5,35,37 Two studies, one conducted at United Kingdomand the other at Malaysia, used both ATP-30 and AMI as done in our study. 23,30,37 These scales tend to assess attitudes related to Psychiatry looking upon the following four aspects: Psychiatric patients and psychiatric illness, Psychiatrist and subject of Psychiatry, Psychiatric knowledge and teaching and Psychiatric treatment and hospitals. ${ }^{5}$

We intended to assess the attitude towards mental illness and Psychiatry among medical students and interns in a University Teaching Hospital using two well-known scales' keeping in facts from earlier studies done at various centers all over the world. ${ }^{23,37}$ We came across only one Nepali study which was conducted more than a decade ago. ${ }^{36}$ Hence, we tried to explore this issue repeatedly studied in most parts of the world in our own hospital setting.

It was a cross-sectional questionnaire based study, intending only a group-wise comparison among the students of the first and final semester, medical students and interns and sex-wise comparison among the males and females in contrast to some of the studies which compared the attitudes among the students before and after teaching or training sessions. ${ }^{26,30,36}$ A study in UK made a comparison between old and new curricula; ${ }^{23}$ while a Greek study compared two groups of students belonging to different batches; ${ }^{8}$ and a Pakistan study compared the students of public and private medical institutes. ${ }^{38}$ 
We did not translate the scales which we had obtained in English version considering the fact that the medium of instruction among our medical students was English, similar was the case in a Pakistan study which also used the English version of ATP-30.5,37

On cross-sectional analysis, we found that our medical students and interns had a neutral or positive attitude towards most of the aspects of mental illness and Psychiatry keeping with the findings from some recent studies done at Pakistan, Malaysia and United Kingdom; $;, 23,30,35$ and in contrast to an earlier study done at Australiaand India. ${ }^{6,7}$ A WHO study also reported negative attitude towards mental illnesses among the medical students. ${ }^{3}$ Only a few items in both the scales showed significantly more positive views on different group and sex-wise comparison as described above.

We also intended to quantify the choices of specialty made by the study participants for their future career but 96 (more than $60 \%$ ) of them were found to be undecided regarding the same. Indecision was found even among the ninth semester students and the interns. Similar findings were seen in an Iran study which highlighted the career indecision to be an important concern for practitioners, researchers, and educators all over the world. ${ }^{34}$

Similarly, our attempt to analyze whether family history of mental illnesses has any significant effect on the medical students' attitude towards Psychiatry, as documented in a Pakistan study, was not successful as almost a quarter of them did not enter anything in the option, while more than two-thirds denied presence of any family history illustrating the worldwide stigma against Psychiatry. ${ }^{1-3,38}$

Our study was not without any limitations. Sample size was small despite prior explanation regarding the study to all the medical students and interns in our institute. Even the participants who consented for the study did not respond completely, left some items on AMI and demographic details blank. Furthermore, as we took the participants from only one institute that too only from the first, sixth and ninth semester, generalization of the results is difficult. Cross-sectional nature of the study and absence of any control groups might not have served our purpose of assessing the attitude and ascertaining the importance of undergraduate education in Psychiatry. Some observed differences on groupwise and sex-wise comparison may be attributed solely to the cohort effect. Similarly, as we used the same English version of the two scales without translation or adaptation to our study population, some statistical biases cannot be ruled out.

Further studies are needed to assess the attitude of Nepali medical students towards mental illness and Psychiatry with large population of medical students, interns and medical officers from different medical colleges using scales well adapted to our own population. Results from a study comparing the attitude towards Psychiatry before and after a formal training in Psychiatry would have visualized the importance of Psychiatry among the undergraduate medical students.

However, the results obtained so far in this study has shown clearly that our medical students held almost positive attitude towards various aspects of mental illness as a disease and Psychiatry as a medical subspecialty which would definitely improve if we could make some improvements in the existing curriculum on teaching learning activities in Psychiatry.

\section{CONCLUSIONS}

Overall attitudes towards mental illness and Psychiatry among the medical students and interns in our Medical School were positive or neutral. A further study with medical students from different institutional background is needed to get a detail nationwide picture that can be implemented in future academic and professional practice.

\section{REFERENCES}

1. World Health Organization. Mental health: new understanding, new hope. [Online]. 2001 [cited 2012 Apr 4]; Available from: URL: http://www.who.int/whrl

2. World Health Organization and World Organization of Family Doctors (WONCA). Integrating mental health into primary care: a global perspective. [Internet]. Singapore: WHO Library Cataloguing-in-Publication Data; 2008. [cited 2012 Apr 4]. Available from: URL: http://www.who.int/ mental_health/policy/Mental\%20health\%

3. World Health Organization. Investing in mental health. Geneva: WHO;2003.
4. Feifel D, Moutier CY, Swerdlow NR. Attitudes toward psychiatry as a prospective career among students entering medical school. Am J Psychiatry. 1999 Sep;156(9):1397-402.

5. Khan SA, Yousafzai AU, Mehir RK, Inam-ul-Haq. Attitude of medical students towards psychiatry in NWFP. J Ayub Med Coll Abbottabad. 2008 Jul-Sep;20(3):44-6.

6. Malhi GS, Parker GB, Parker K, Carr VJ, Kirkby KC, Yellowlees $\mathrm{P}$, et al. Attitudes toward psychiatry among students entering medical school. ActaPsychiatr Scand. 2003 Jun;107(6):424-9. 
7. Prabhakaran RR, Murugappan M, Devar JV. Undergraduate psychiatric education and attitude of medical students towards psychiatry. Indian Journal of Psychological Medicine. 1989;12:37-48.

8. Garyfallos G, Adamanopoulou A, Lavrentiadis G, Giouzepas J, Parashos A, Dimitriou E. Medical Students' Attitudes Toward Psychiatry in Greece. Acad Psychiatry. 1998;22:92-7.

9. Eagle PF, Marcos LR. Factors in medical students' choice of psychiatry. Am J Psychiatry. 1980 Apr;137(4):423-7.

10. Shokoohi-Yekta M, Retish P. Attitudes of Chinese and American male students toward mental illness. Int J Soc Psychiatry. 1991;87:192-200.

11. Nielsen AC 3rd, Eaton JS Jr. Medical students' attitudes about psychiatry. Implications for psychiatric recruitment. Arch Gen Psychiatry. 1981 Oct;38(10):1144-54.

12. Taintor $Z$, Nielsen AC III. The extent of the problem: a review of the data concerning the declining choice of psychiatric careers. J Psychiatric Educ. 1981;5:63-87.

13. Singer P, Dornbush RL, Brownstein EJ, Freedman AM. Undergraduate psychiatric education and attitudes of medical students towards psychiatry. Compr Psychiatry. 1986 Jan-Feb;27(1):14-20.

14. Niaz U, Hassan S, Hussain H, Saeed S. Attitudes towards Psychiatry in Pre-clinical clerkships and Post-clinical clerkship in different medical colleges of Karachi. Pak J Med Sci. 2003;19:253-63.

15. Lloyd GG, Mayou RA. Liaison psychiatry or psychological medicine? Br J Psychiatry. 2003 Jul;183:5-7.

16. Farooq S, Akhter J, Anwar E, Hussain I, Khan SA; Inam-ulHaqJadoon. The attitude and perception of hospital doctors about the management of psychiatric disorders. J Coll Physicians Surg Pak. 2005 Sep;15(9):552-5.

17. Ministry of Health and Family Welfare.National Mental Health Programme. India: Government of India; 1982.

18. Das MP, Chandrasena RD. Medical students' attitude towards psychiatry. Can J Psychiatry. 1988 Dec;33(9):783-7.

19. Ghadirian AM, Engelsmann F. Medical students' attitude towards psychiatry: a ten-year comparison. Med Educ. 1982 Jan;16(1):39-43.

20. Wilkinson DG, Greer S, Toone BK. Medical students attitudes to psychiatry. Psychol Med. 1983 Feb;13(1):185-92.

21. Rahim A, El-Assra A. Saudi medical students' attitudes toward psychiatry. Annals of Saudi Medicine. 1989;9:190-4.

22. Koh KB. Medical students' attitudes toward psychiatry in a Korean medical college. Yonsei Med J. 1990 Mar;31(1):60-4.

23. Singh SP, Baxter H, Standen P, Duggan C. Changing the attitudes of 'tomorrow's doctors' towards mental illness and psychiatry: a comparison of two teaching methods. Med Educ. 1998 Mar;32(2):115-20.

24. Lau AY, Offord DR. A study of student attitudes toward a psychiatric clerkship. J Med Educ. 1976 Nov;51(11):919-28.
25. Nielsen AC 3rd, Eaton JS Jr. Medical students' attitudes about psychiatry. Implications for psychiatric recruitment. Arch Gen Psychiatry. 1981 Oct;38(10):1144-54.

26. Bulbena A, Pailhez G, Coll J. Changes in the attitudes towards psychiatry among Spanish medical students during training in psychiatry. Eur J Psychiatry. 2005;19:79-87.

27. Rao TSS, Rao KN, Rudrappa DA, Reddy DR. Medical students' attitudes to psychiatry. Indian Journal of Psychological Medicine. 1989;12:29-35.

28. Alexander PJ, Kumaraswamy N. Impact of medical school experiences on senior medical students' interest in psychiatry. Indian J Psychiatry. 1995 Jan-Mar;37(1):31-4.

29. Kuruvilla1 PK, John JK. Knowledge and attitude about psychiatric illness among interns. Indian J Psychiatry. 1991 Jan-Mar;33(1):11-5.

30. Tan SMK, Azmi MT, Reddy JP, Shaharom MH, Rosdinom R, Maniam T, et al. Does clinical exposure to patients in medical school affect trainee doctors' attitudes towards mental disorders and patients?--A pilot study. Med J Malaysia. 2005;60(3):328- 37.

31. Bakewell LE, Ewingj A, Rowse BA. Experimental clerkship for pre-freshman medical students. Journal of Medical Education. 1971;46:156

32. Clardy JA, Thrush CR, Guttenberger VT, et al. The junior-year psychiatric clerkship and medical students' interest in psychiatry. Acad Psychiatry. 2000;24:35-40.

33. Nielsen AC: Choosing psychiatry: the importance of psychiatric education in medical school. Am J Psychiatry. 1980;137:428-31.

34. Parsa S, Aghazadeh A, Nejatisafa AA, Amini H, Mohammadi MR, Mostafazadeh B, et al. Freshmen versus interns'specialty interests. Arch Iran Med. 2010 Nov;13(6):509-15.

35. Maidment R, Livingston G, Katona M, Whitaker E, Katona C. Carry on shrinking: career intentions and attitudes to psychiatry of prospective medical students. Psychiatr Bull. 2003;27:30-2.

36. Chadda RK, Singh MM. Awareness about psychiatry in undergraduate medical students in Nepal. Indian J Psychiatry. 1999 Jul;41(3):211-6.

37. Burra P, Kalin R, Leichner P, Waldron JJ, Handforth JR, Jarrett FJ, et al. The ATP 30-a scale for measuring medical students attitudes to psychiatry. Med Educ. 1982 Jan;16(1):31-8.

38. Aslam M, Taj T, Ali A, Badar N, Saeed F, Abbas M, et al Psychiatry as a career: a survey of factors affecting students' interest in psychiatry as a career. Mcgill J Med. 2009 Jan;12(1):7-12

39. Nevid J, Morrison J. Attitudes toward mental illness: the construction of the Libertarian Mental Health Ideology Scale. J Human Psychology. 1980;20:71-85. 


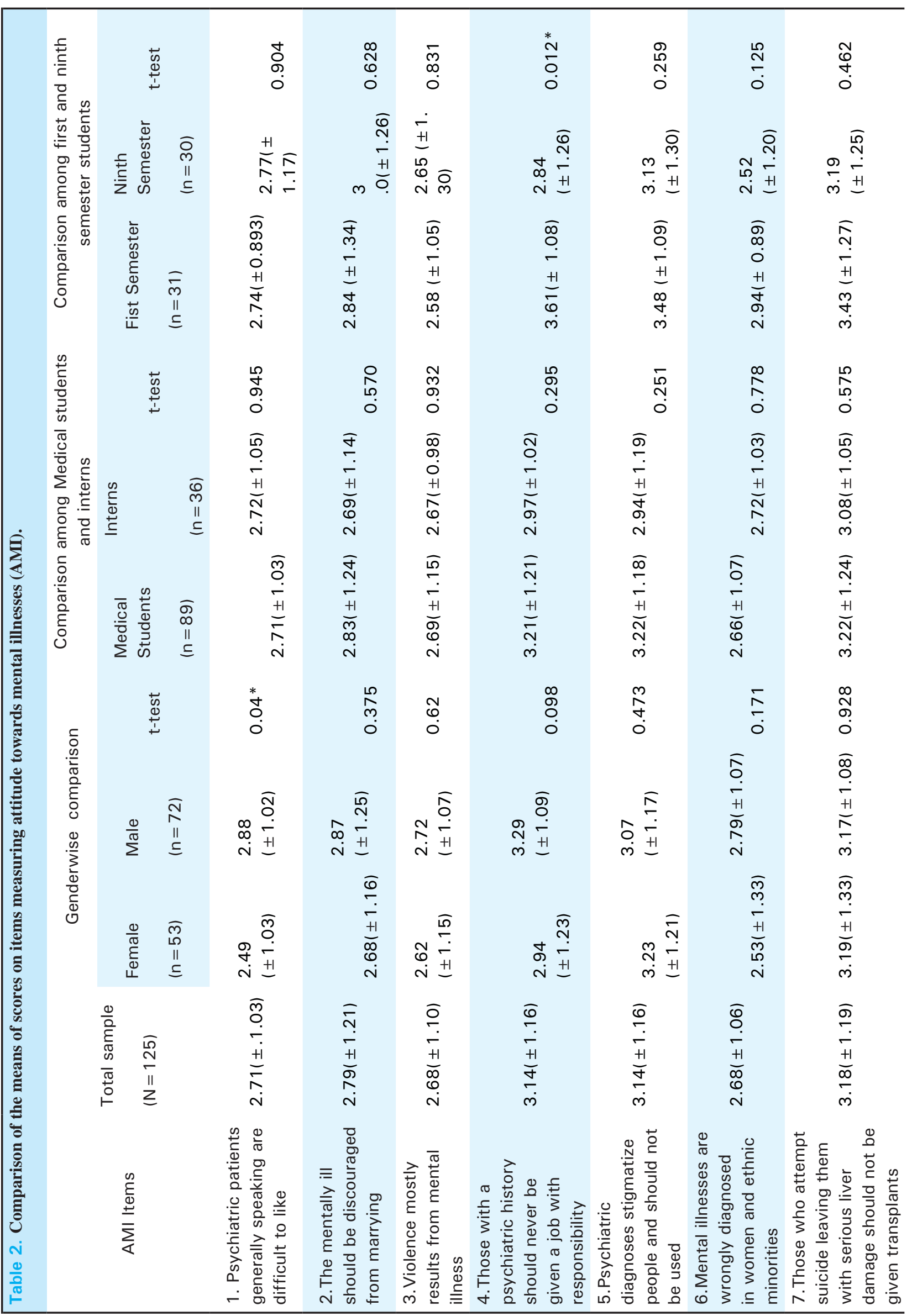




\begin{tabular}{|c|c|c|c|c|c|c|c|c|c|c|c|c|}
\hline $\begin{array}{l}\stackrel{0}{0} \\
\stackrel{\sigma}{0} \\
0\end{array}$ & $\begin{array}{l}\infty \\
\stackrel{\infty}{\circ} \\
0 \\
0\end{array}$ & $\frac{\text { lo }}{\frac{8}{0}}$ & $\begin{array}{l}\stackrel{9}{\circ} \\
\stackrel{0}{0}\end{array}$ & 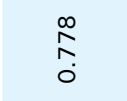 & $\begin{array}{l}\stackrel{9}{0} \\
\hat{0} \\
0\end{array}$ & 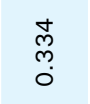 & $\begin{array}{l}\text { ** } \\
\stackrel{8}{\circ} \\
0\end{array}$ & $\begin{array}{l}: \\
\vdots \\
0\end{array}$ & 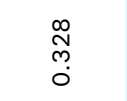 & $\begin{array}{l}\text { 苟 } \\
\stackrel{0}{0} \\
0\end{array}$ & $\frac{\circ}{\frac{1}{0}}$ & 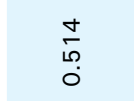 \\
\hline $\begin{array}{l}\overline{0} \\
\stackrel{+}{+} \\
+1 \\
\stackrel{+}{\sigma} \\
\stackrel{j}{i}\end{array}$ & $\begin{array}{l}\underset{J}{J} \\
\dot{+} \\
\stackrel{+}{+1} \\
\hat{\infty} \\
\stackrel{N}{i}\end{array}$ & $\begin{array}{l}\sqrt{5} \\
9 \\
0 \\
+1 \\
\hat{+} \\
\dot{f} \\
\dot{n}\end{array}$ & 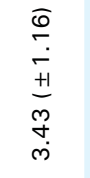 & $\begin{array}{l}\bar{o} \\
\stackrel{p}{+} \\
++1 \\
\stackrel{+}{m} \\
\stackrel{N}{i}\end{array}$ & 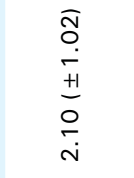 & 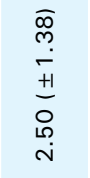 & 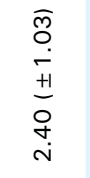 & $\begin{array}{l}\text { J } \\
\stackrel{+}{+} \\
+1 \\
0 \\
i \\
i\end{array}$ & 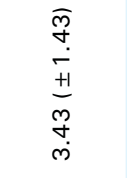 & 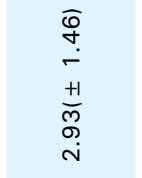 & $\begin{array}{l}\bar{\sigma} \\
\stackrel{\sigma}{+} \\
\dot{+1} \\
\overline{0} \\
\dot{+}\end{array}$ & $\begin{array}{l}\bar{\emptyset} \\
\stackrel{+}{+} \\
+ \\
\stackrel{+}{m} \\
\stackrel{i}{N}\end{array}$ \\
\hline $\begin{array}{l}\widehat{D} \\
o \\
o \\
+1 \\
\hat{i} \\
\stackrel{0}{i} \\
\text { in }\end{array}$ & 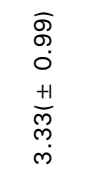 & $\begin{array}{l}\bar{\Omega} \\
\stackrel{5}{0} \\
0 \\
+1 \\
\infty \\
\infty \\
\infty \\
\infty\end{array}$ & $\begin{array}{l}\bar{a} \\
\dot{0} \\
\dot{0} \\
+1 \\
\hat{0} \\
\dot{m} \\
\dot{m}\end{array}$ & 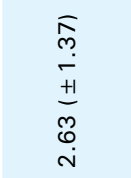 & 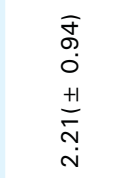 & 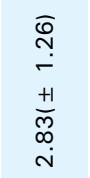 & 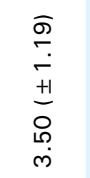 & 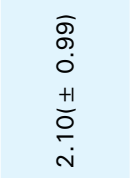 & 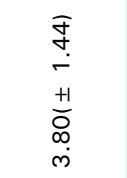 & $\begin{array}{l}\bar{\sigma} \\
\circ \\
0 \\
+1 \\
+1 \\
0 \\
0 \\
0\end{array}$ & 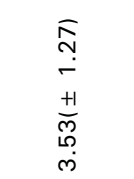 & $\begin{array}{l}\bar{\sigma} \\
\stackrel{+}{-} \\
+ \\
\stackrel{+}{m} \\
\stackrel{N}{d}\end{array}$ \\
\hline $\begin{array}{l}: \\
\stackrel{0}{0} \\
0\end{array}$ & $\begin{array}{l}\text { Ĩ } \\
\text { Ȯ }\end{array}$ & $\begin{array}{l}\frac{0}{\sigma} \\
\dot{0} \\
0\end{array}$ & 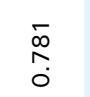 & $\begin{array}{l}\widetilde{N} \\
\substack{\infty \\
0 \\
0}\end{array}$ & $\begin{array}{l}\stackrel{*}{*} \\
\stackrel{\circ}{0} \\
0 \\
0\end{array}$ & 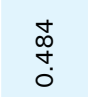 & $\stackrel{m}{\stackrel{0}{0}}$ & $\begin{array}{l}0 \\
\stackrel{0}{0} \\
0 \\
0\end{array}$ & $\begin{array}{l}\stackrel{*}{\sim} \\
\stackrel{0}{0} \\
\stackrel{0}{0}\end{array}$ & $\begin{array}{l}\text { む̊ } \\
\stackrel{0}{0}\end{array}$ & $\begin{array}{l}\stackrel{a}{0} \\
0 \\
0\end{array}$ & $\begin{array}{l}\stackrel{9}{a} \\
\stackrel{0}{0}\end{array}$ \\
\hline $\begin{array}{l}\widehat{N} \\
o \\
0 \\
+1 \\
+1 \\
\infty \\
\infty \\
\text { i. }\end{array}$ & $\begin{array}{l}\bar{o} \\
\dot{\alpha} \\
\stackrel{+1}{+} \\
\stackrel{m}{m} \\
\dot{m}\end{array}$ & 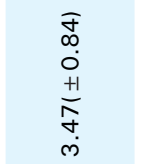 & 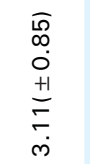 & $\begin{array}{l}\widehat{m} \\
\stackrel{+}{+} \\
+1 \\
\dot{+} \\
\stackrel{j}{j} \\
\dot{j}\end{array}$ & $\begin{array}{l}\widehat{\bar{g}} \\
0 \\
0 \\
+1 \\
+\infty \\
\stackrel{+}{0} \\
\stackrel{n}{N}\end{array}$ & \begin{tabular}{l}
$\mathbb{1}$ \\
$\infty$ \\
0 \\
+1 \\
+1 \\
\multirow{2}{*}{} \\
$\stackrel{N}{N}$
\end{tabular} & $\begin{array}{l}\widehat{\pi} \\
\infty \\
0 \\
+1 \\
+1 \\
\stackrel{0}{\circ} \\
\hat{i}\end{array}$ & 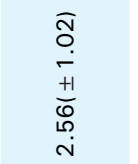 & $\begin{array}{l}\bar{\Phi} \\
\stackrel{亠}{+} \\
\stackrel{+1}{\sigma} \\
\stackrel{\Gamma}{m}\end{array}$ & 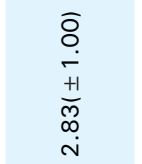 & $\begin{array}{l}\widehat{M} \\
0 \\
0 \\
+1 \\
+0 \\
0 \\
0 \\
j \\
\dot{j}\end{array}$ & $\begin{array}{l}\pi \\
0 \\
0 \\
+1 \\
+1 \\
0 \\
\stackrel{0}{0} \\
\text { in }\end{array}$ \\
\hline 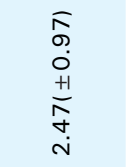 & 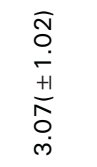 & 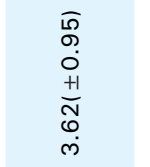 & $\begin{array}{l}\bar{\sigma} \\
\dot{+} \\
\dot{+1} \\
\dot{0} \\
\dot{m}\end{array}$ & 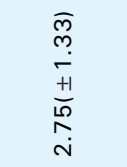 & $\begin{array}{l}\widehat{a} \\
\infty \\
o \\
+1 \\
+1 \\
\frac{\sigma}{5} \\
\bar{i}\end{array}$ & 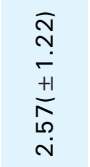 & $\begin{array}{l}\frac{\sigma}{\Phi} \\
\stackrel{+}{+} \\
\frac{+1}{\sigma} \\
\dot{m}\end{array}$ & 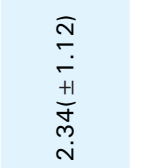 & 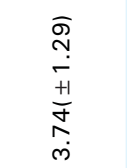 & $\begin{array}{l}\stackrel{\infty}{\infty} \\
\stackrel{-}{+} \\
\stackrel{+1}{\stackrel{\omega}{n}} \\
\stackrel{m}{\infty}\end{array}$ & $\begin{array}{l}\frac{\sigma}{0} \\
\stackrel{+}{+} \\
+1 \\
\stackrel{+1}{\circ} \\
\dot{m}\end{array}$ & 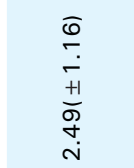 \\
\hline $\begin{array}{l}0 \\
\hat{0} \\
0\end{array}$ & $\begin{array}{l}\stackrel{*}{N} \\
\stackrel{N}{0} \\
\stackrel{0}{0}\end{array}$ & 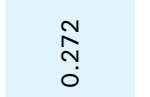 & 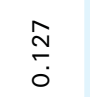 & $\begin{array}{c}\stackrel{0}{\infty} \\
\infty \\
0\end{array}$ & $\begin{array}{l}\infty \\
0 \\
0 \\
0\end{array}$ & $\begin{array}{l}* \\
0 \\
\tilde{y} \\
0 \\
0\end{array}$ & $\begin{array}{l}\infty \\
\stackrel{8}{0} \\
\stackrel{0}{0}\end{array}$ & $\begin{array}{l}8 \\
\stackrel{\leftrightarrow}{0} \\
\stackrel{0}{0}\end{array}$ & $\begin{array}{l}\text { No } \\
\text { D. } \\
0 \\
0\end{array}$ & $\begin{array}{l}\stackrel{\leftrightarrow}{0} \\
\stackrel{0}{0}\end{array}$ & $\begin{array}{l}0 \\
\text { o. } \\
0\end{array}$ & 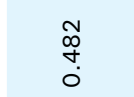 \\
\hline 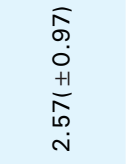 & 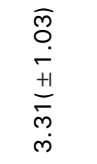 & 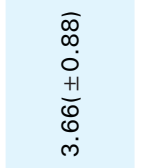 & $\begin{array}{l}\widehat{1} \\
0 \\
0 \\
+1 \\
+1 \\
0 \\
\stackrel{0}{0} \\
\text { in }\end{array}$ & $\begin{array}{l}\frac{\infty}{\infty} \\
\stackrel{+}{+} \\
+1 \\
\stackrel{+}{+} \\
\stackrel{N}{N}\end{array}$ & 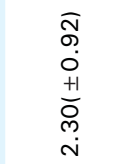 & $\begin{array}{l}\frac{J}{\sigma} \\
\stackrel{+}{+} \\
\stackrel{+1}{N} \\
\stackrel{N}{N}\end{array}$ & $\begin{array}{l}\mathbb{5} \\
\dot{0} \\
+1 \\
+1 \\
0 \\
\dot{j}\end{array}$ & 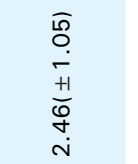 & 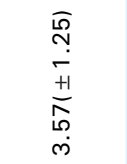 & 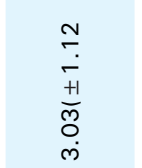 & 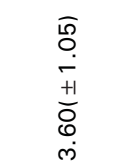 & 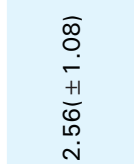 \\
\hline $\begin{array}{l}\widehat{T} \\
0 \\
0 \\
+1 \\
+1 \\
\stackrel{1}{0} \\
\stackrel{n}{i}\end{array}$ & $\begin{array}{l}\bar{o} \\
\circ \\
\dot{0} \\
+1 \\
\bar{\sigma} \\
\dot{\sigma}\end{array}$ & 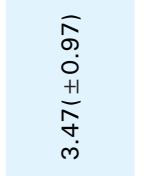 & 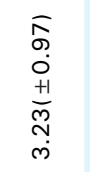 & 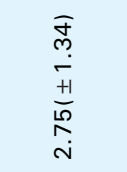 & 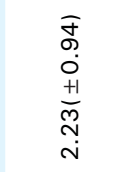 & $\begin{array}{l}\overline{0} \\
\stackrel{0}{+} \\
\stackrel{+1}{+\infty} \\
\stackrel{\infty}{\infty} \\
\stackrel{N}{N}\end{array}$ & 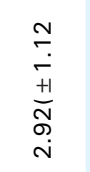 & 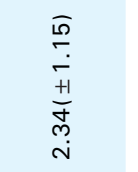 & 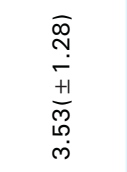 & $\begin{array}{l}\bar{\sigma} \\
\stackrel{+}{+} \\
+1 \\
\stackrel{+1}{0} \\
\stackrel{m}{j}\end{array}$ & $\begin{array}{l}\bar{\infty} \\
\leftarrow \\
+ \\
+1 \\
\infty \\
0 \\
\dot{\infty} \\
\dot{\infty}\end{array}$ & 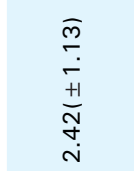 \\
\hline 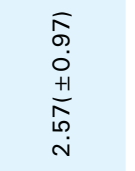 & 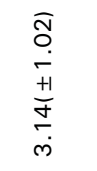 & 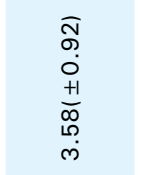 & $\begin{array}{l}\bar{\Xi} \\
\circ \\
0 \\
+1 \\
+1 \\
\\
\dot{m}\end{array}$ & 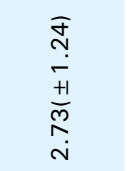 & $\begin{array}{l}\widehat{N} \\
o \\
0 \\
+1 \\
\stackrel{N}{N} \\
\stackrel{i}{N}\end{array}$ & 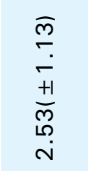 & $\begin{array}{l}\vec{\sigma} \\
\stackrel{+}{+} \\
\dot{+} \\
\dot{0} \\
\dot{j}\end{array}$ & 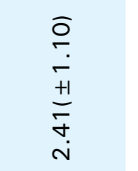 & 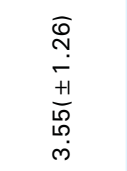 & $\begin{array}{l}\underset{+}{+} \\
\stackrel{+1}{m} \\
\frac{+}{m}\end{array}$ & $\begin{array}{l}\bar{I} \\
\stackrel{+}{+} \\
+1 \\
0 \\
0 \\
\dot{j}\end{array}$ & 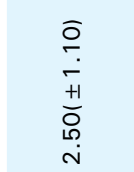 \\
\hline 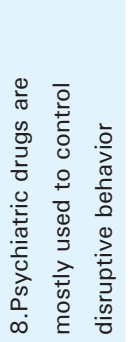 & 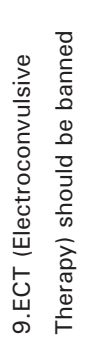 & 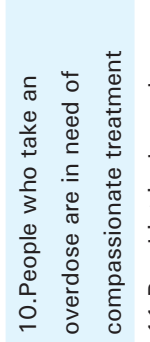 & 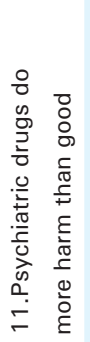 & 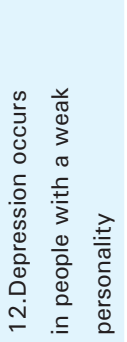 & 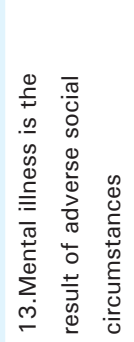 & 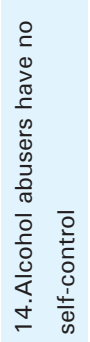 & 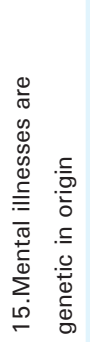 & 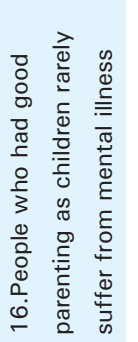 & 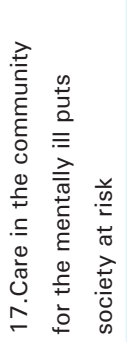 & 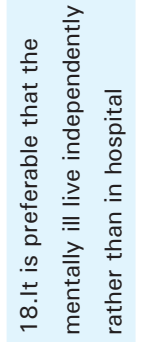 & 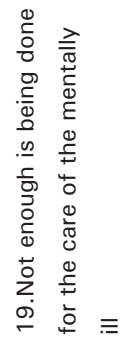 & 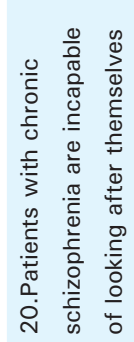 \\
\hline
\end{tabular}




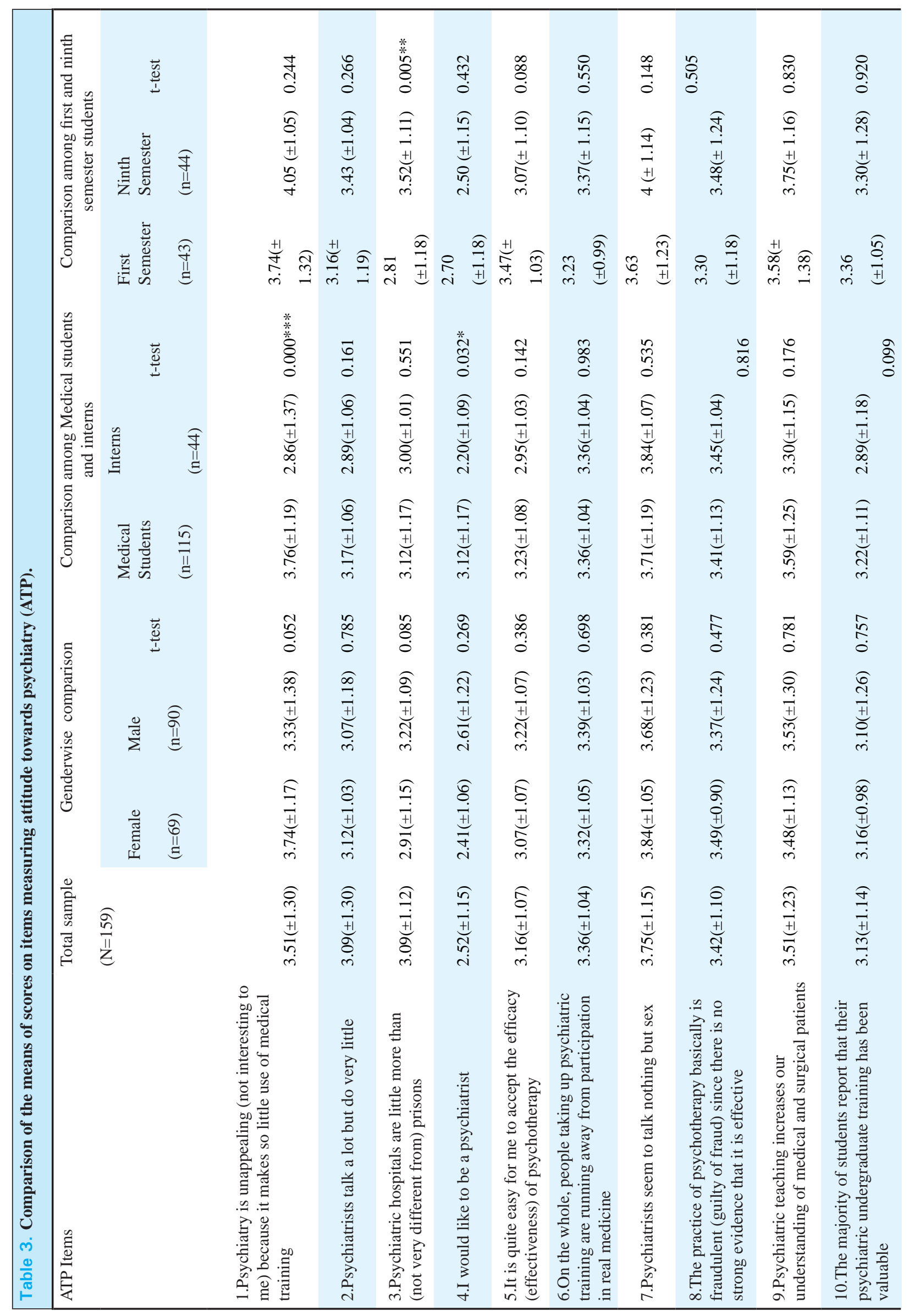




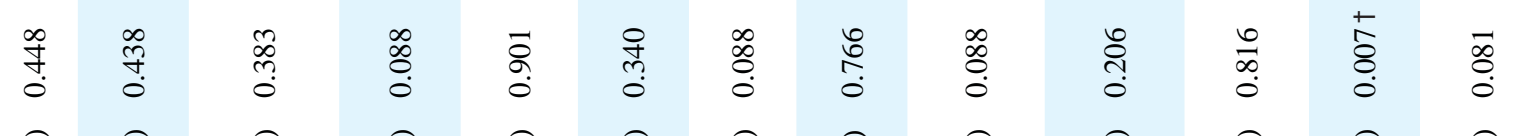

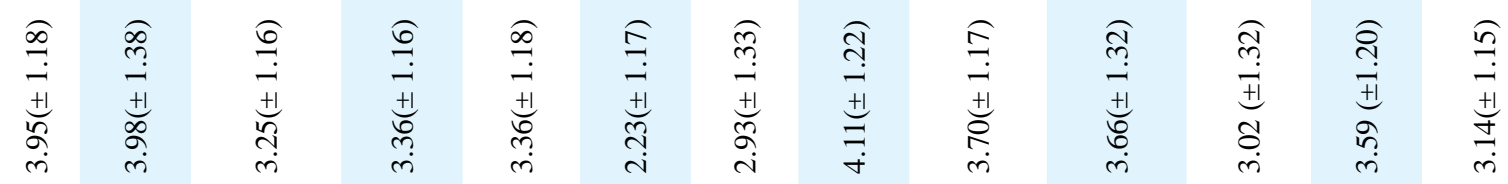

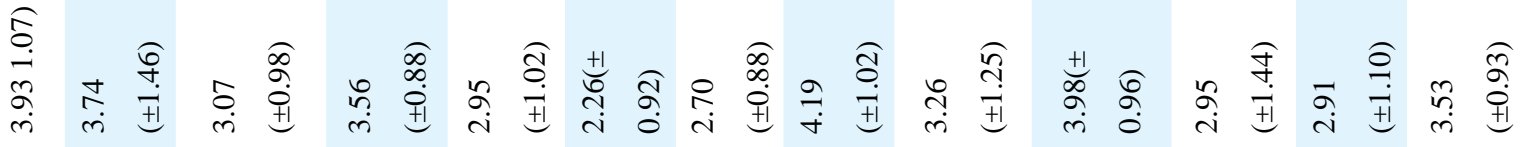

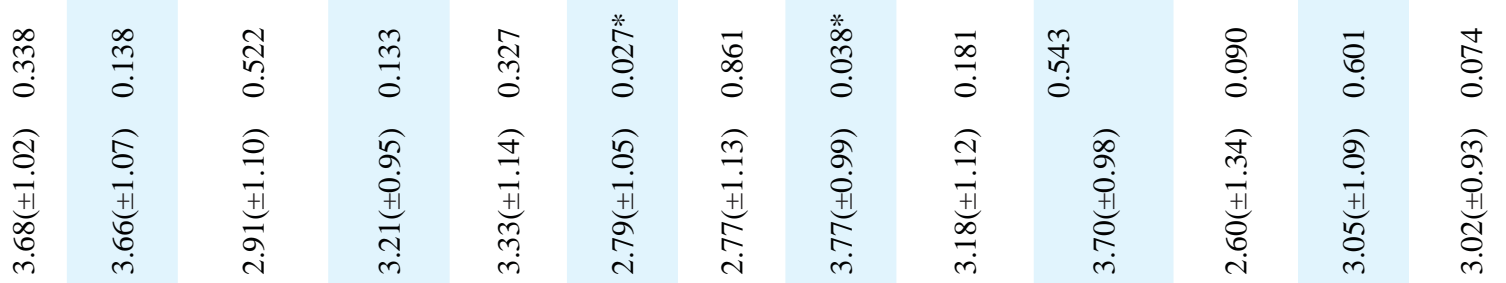

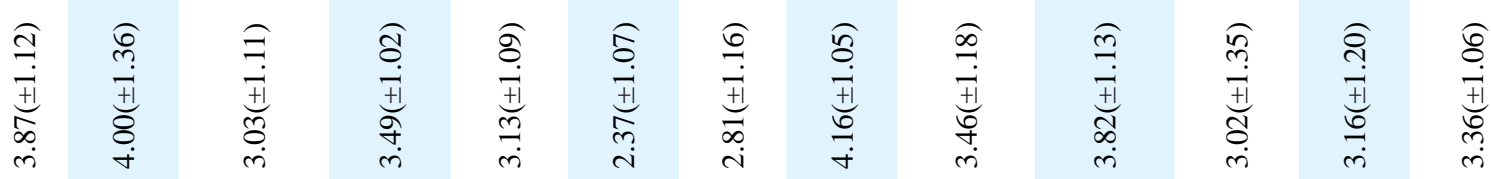

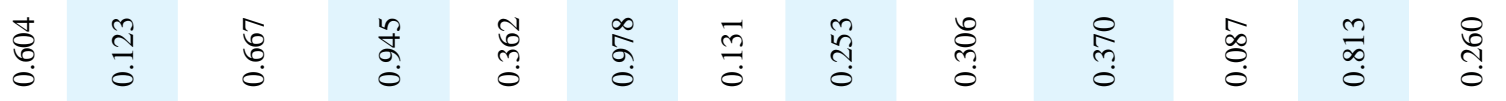

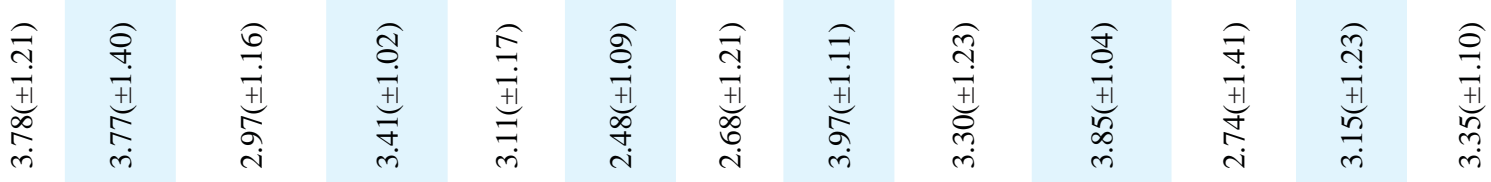

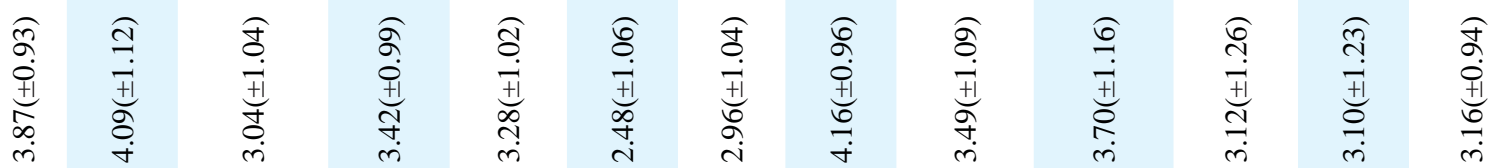

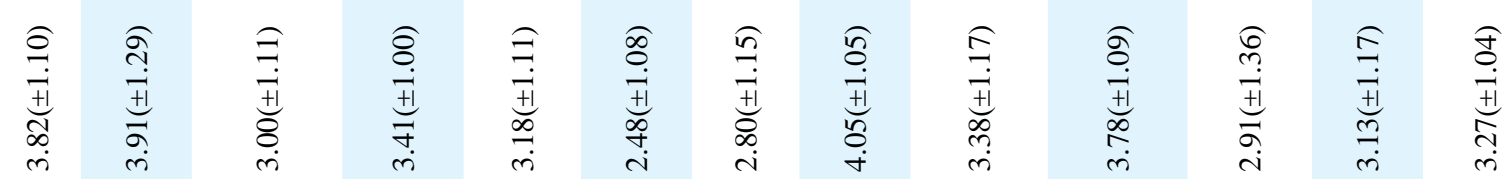

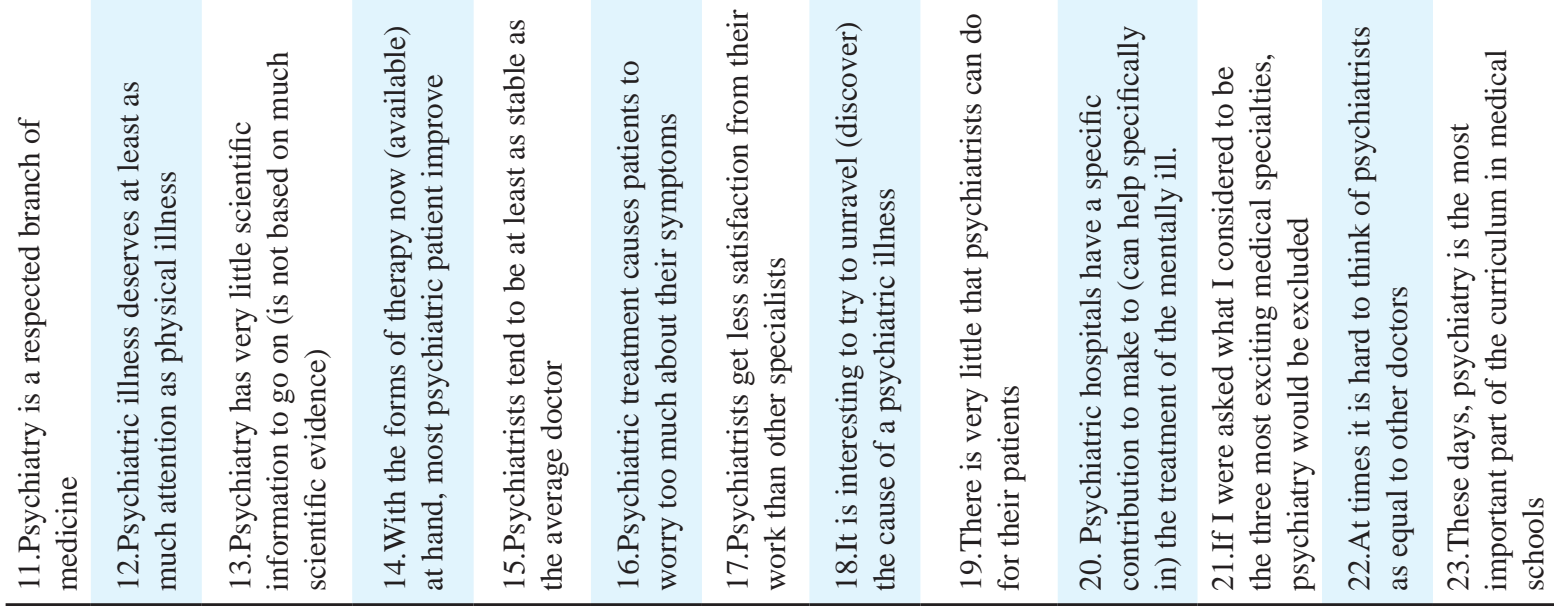




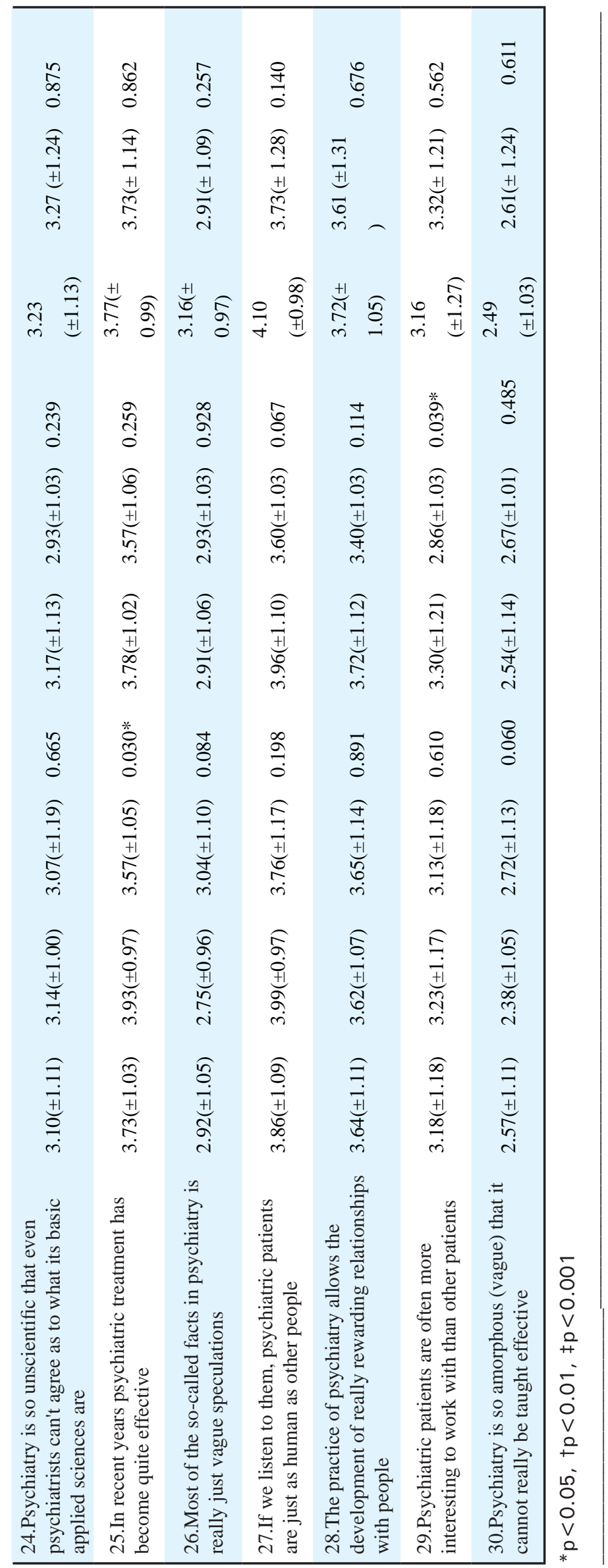

